\title{
Enucleación de odontoma compuesto maxilar con regeneración ósea guiada
}

\section{Compound maxillary odontoma enucleation with guided bone regeneration}

\author{
Martínez Martínez A*, Gómez Arcila V**, Luján Pardo MP**, Flórez de Hoyos L**, \\ Díaz Caballero A**
}

\section{RESUMEN}

Los odontomas son tumores odontogénicos benignos de los maxilares, asociados con frecuencia a retención dentaria, suelen tener un comportamiento indolente, diagnosticándose en radiografías de rutina. El defecto óseo como consecuencia de la osteotomía durante la enucleación del tumor, es una de las principales secuelas que el clínico debe tener presente por la afección no sólo al tejido duro sino también al tejido suave circundante, por esta razón, se han sugerido diferentes materiales para regenerar el tejido óseo perdido. Se reporta caso de paciente masculino de 33 años de edad que asistió a consulta manifestando insatisfacción estética por persistencia de órgano temporal 51 causado por la presencia de un odontoma compuesto, cuyo diagnóstico se corroboró clínica e histológicamente. El defecto óseo residual a la enucleación de dicho tumor se rellenó con hidroxiapatita no reabsorbible, para su posterior restauración definitiva. En el control postoperatorio, se observó resultados estéticos y funcionales satisfactorios.

Palabras clave: Odontoma compuesto, hidroxiapatita, injerto óseo, regeneración ósea (Decs Bireme).

\section{SUMMARY}

Odontomas are the most common maxillary beningn odontogenic tumours, who often causing dental retention, most odontomas are asymptomatic and are discovered during routine radiographic investigations. Furthermore, one of the most severe effect that the clinician must take into account is the large bone loss after enucleation of the tumor, affecting not only bone tissue, but also the surrounding soft tissue, however, many materials have been suggested for filled these types of defects bone. We report a case of a 33-year-old men who express aesthetic disagreement due to persistence of temporary tooth 51 caused by the presence of a compound odontoma, whose diagnosis was confirmed clinical and histologically. The residual bone defect after enucleation of the tumor was filled with non-resorbable hydroxyapatite, for subsequent final restoration. In the postoperative control was observed satisfactory aesthetic and functional results.

Key words: Odontoma, hydroxyapatite, bone graft, bone regeneration (MeSH).

Fecha de recepción: 19 de mayo de 2013.

Aceptado para publicación: 8 de julio de 2013.

* Departamento de Cirugía y Patología Oral. Facultad de Odontología. Universidad del Sinu. Cartagena de Indias. Colombia.

** Grupo de Investigaciones GITOUC. Facultad de Odontología. Universidad de Cartagena. Cartagena de Indias. Colombia.

Martínez Martínez A, Gómez Arcila V, Luján Pardo MP, Flórez de Hoyos L, Díaz Caballero. Enucleación de odontoma compuesto maxilar con regeneración ósea guiada. Av. Odontoestomatol 2013; 29 (6): 287-290. 


\section{INTRODUCCIÓN}

Los odontomas son los tumores benignos odontogénicos mixtos más frecuentes de los maxilares, formados por una mezcla de células odontogénicas, células epiteliales y mesenquimales. La etiología es desconocida pero se relaciona con factores traumáticos, infecciosos, factores hereditarios, alteraciones durante la embriogénesis, hiperactividad odontoblástica y mutaciones genéticas $(1,2)$. La Organización Mundial de la Salud clasifica odontomas desde el punto de vista histopatológico como: odontoma complejo y compuesto, el primero, corresponde a una alteración de la odontogénesis. La morfodiferenciación es escasa; hay poca semejanza con la forma del diente normal. Los tejidos dentales están bien formados pero muestran una disposición más o menos desordenada, mientras que, el segundo tipo, es un conglomerado de esmalte, dentina, cemento y pulpa; los tejidos dentales son normales pero su tamaño y la conformación se alteran. Estos últimos se localizan en la región anterior del maxilar, entre las raíces y sobre las coronas de un diente retenido (3).

Estos tumores benignos no tienen predilección por género aunque existe una ligera predilección por el sexo masculino. El 75\% de los casos suelen diagnosticarse antes de la segunda década de la vida, debido a que existe un retraso en la erupción dental permanente. Suelen ser asintomáticos y su hallazgo casual tras realizar un estudio radiográfico habitual, en donde se observan varios dentículos deformes rudimentarios bien delimitados, es decir, masas radiopacas de márgenes irregulares que adopta una configuración similar a dientes con un borde periférico radiolúcido (odontoma compuesto) o una masa irregular radiopaca (odontoma complejo) rodeados por una zona radiotransparente, que es la cápsula fibrosa que circunda la lesión. El tratamiento es quirúrgico y consiste en su enucleación, tratando de conservar el diente permanente retenido, planteando en este último alternativas de tratamiento como: abstención quirúrgica, exodoncia quirúrgica o colocación del diente en la arcada mediante ortodoncia (4).

Cuando un tumor odontogénico u otras patologías asociadas como quistes son removidos bajo tratamiento quirúrgico, generan defectos óseos que interfieren con las expectativas estéticas del operador y del paciente. Por lo anterior, muchos han sido los materiales utilizados para rellenar estos tipos de defectos óseos residuales con el objetivo de suturar sobre una superficie firme, evitar empaquetar tiras de gasas, evitar el crecimiento invertido de tejidos, evitar infecciones y sobretodo todo, crear un contorno fisiológico óptimo (5). Recientemente, se ha planteado el uso de injertos aloplásticos, dentro del cual se cita la hidroxiapatita no reabsorbible en forma de gránulos para rellenar cavidades quísticas y defectos óseos creados por los tumores maxilares con resultados prometedores, pues se ha comprobado una osteointegración excelente. Lo anterior indica pues que el uso de materiales sintéticos no reabsorbibles en la reconstrucción de defectos óseos residuales, mejora y acelera la reparación del hueso (6).

\section{DESCRIPCIÓN DEL CASO CLÍNICO}

Paciente masculino de 33 años de edad que acude a consulta odontológica por motivos estéticos, manifestando persistencia de diente temporal en zona anterior. El paciente no reportó ningún antecedente personal y familiar de importancia, y en la exploración de órganos y sistemas no presentó alteraciones considerables para el caso. Al examen intraoral se evidenció persistencia de órgano dentario (OD) 51, ausencia clínica de OD 11 (Figura 1), el estado general del resto de la dentición era normal. Radiográficamente se observó imagen radiopaca de 0,5×0,5 $\mathrm{cm}$ de diámetro, con borde radiolúcido, bien definido, localizado entre los OD 51 y 12, se evidenció múltiples imágenes radiopacas en su interior, de tamaño variable oscilando entre los 2 y $4 \mathrm{~mm}$; además, se observó inclusión de OD 11, en posición alta, adyacente a piso de fosas nasales, en mesioangulación, con raíces poco definidas y ausencia de patología quística asociada (Figura 2).

A partir de los hallazgos clínicos y radiográficos anteriormente descritos, se propuso los siguientes diagnósticos: tumor odontogénico compatible con odontoma compuesto, inclusión dentaria de OD11 y anquilosis de OD 51. En base a estos diagnósticos, se decidió realizar tratamiento quirúrgico, el cual, consistió en enucleación del odontoma con regeneración ósea guiada de la cavidad remanente y abstención quirúrgica en OD 11. La enucleación del 


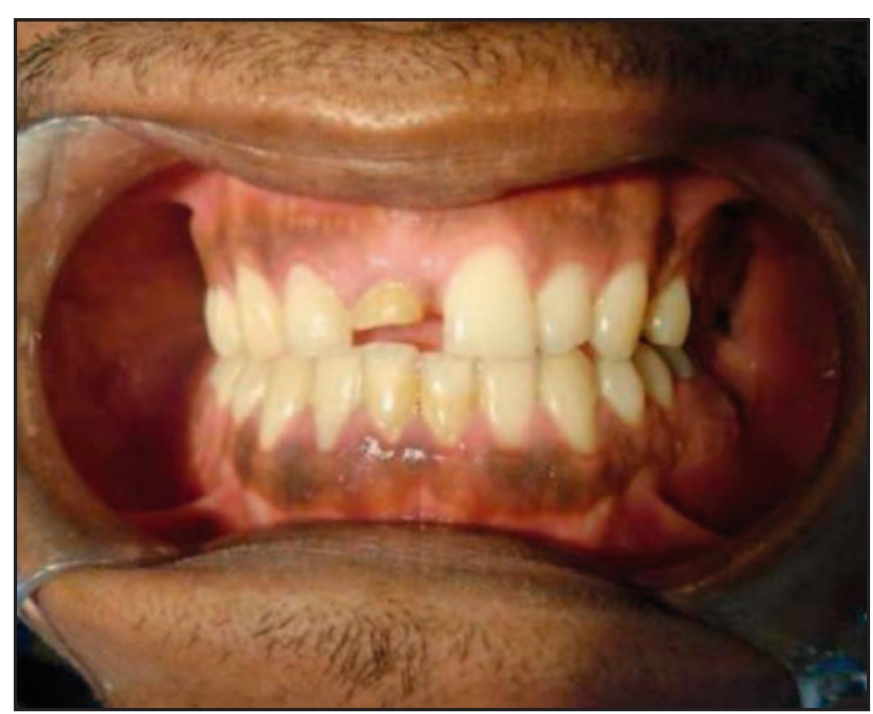

Fig. 1. Persistencia de órgano dental temporal 51 por la presencia del odontoma que retiene el órgano dentario permanente.

odontoma compuesto se inició, previa anestesia local con lidocaína al $2 \%$, diseñando un colgajo de Newman parcial para levantar un colgajo mucoperióstico. La osteotomía se realizó con pieza de mano y fresa 702 con abundante irrigación, de forma controlada y progresiva para la extracción del OD 51 y enucleación del tumor odontogénico asociado (Figura 3), el cual fue enviado a estudio Histopatológico.

Los dentículos fueron extraídos minuciosamente hasta limpiar el lecho quirúrgico por completo, posteriormente, el defecto óseo residual fue rellenado con injerto aloplástico no reabsorbible de hidroxiapatita porosa (Calcitite, Zimmer $\left.{ }^{\circledR}, 40-60\right)$ en forma de gránulos (Figura 4). Los bordes del colgajo se suturaron cuidadosamente con puntos simples ais-

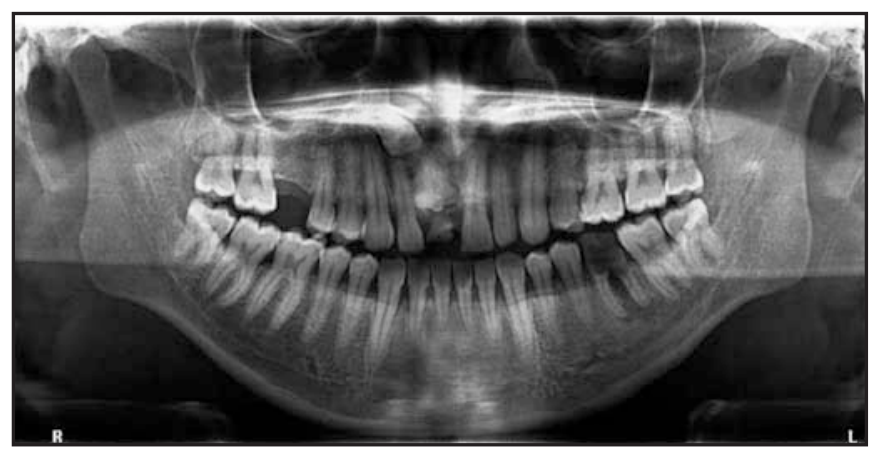

Fig. 2. Imagen radiográfica del odontoma compuesto maxilar.

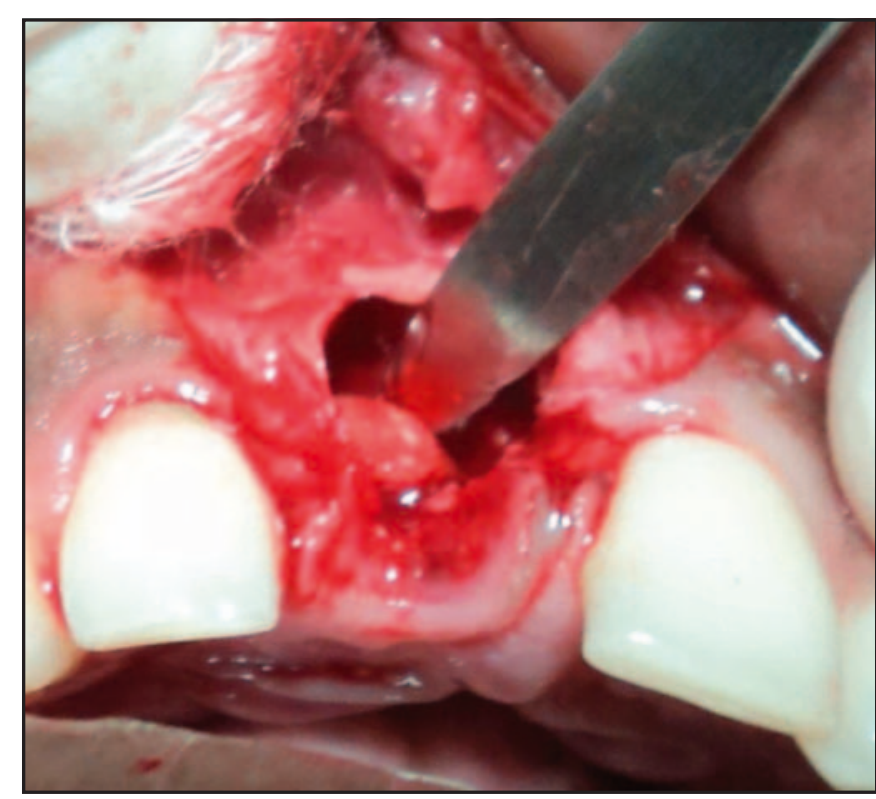

Fig. 3. Enucleación del tumor odontogénico, llevado posteriormente a estudio histopatológico.

lados con seda negra 3-0 (Figura 5). Una vez finalizada la intervención quirúrgica, al paciente se le prescribió: Clindamicina 500 mg, Nimesulide 100 mg y enjuagues con Clorhexidina al $0,12 \% 2$ veces al día por 7 días; impartiendo al pacientes las demás indicaciones postoperatorias necesarias. Se realizó control clínico a los 8, 15 y 60 días en donde se comprobó que el material sintético se mantenía en posición y los tejidos blandos con buen proceso de cicatriza-

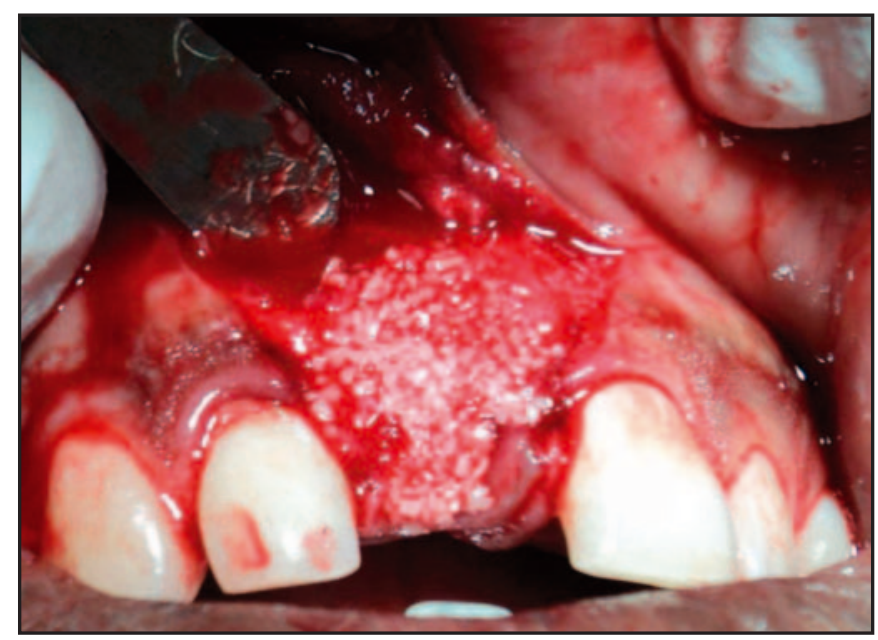

Fig. 4. Colocación de hidroxiapatita porosa no reabsorbible en el sitio quirúrgico. 


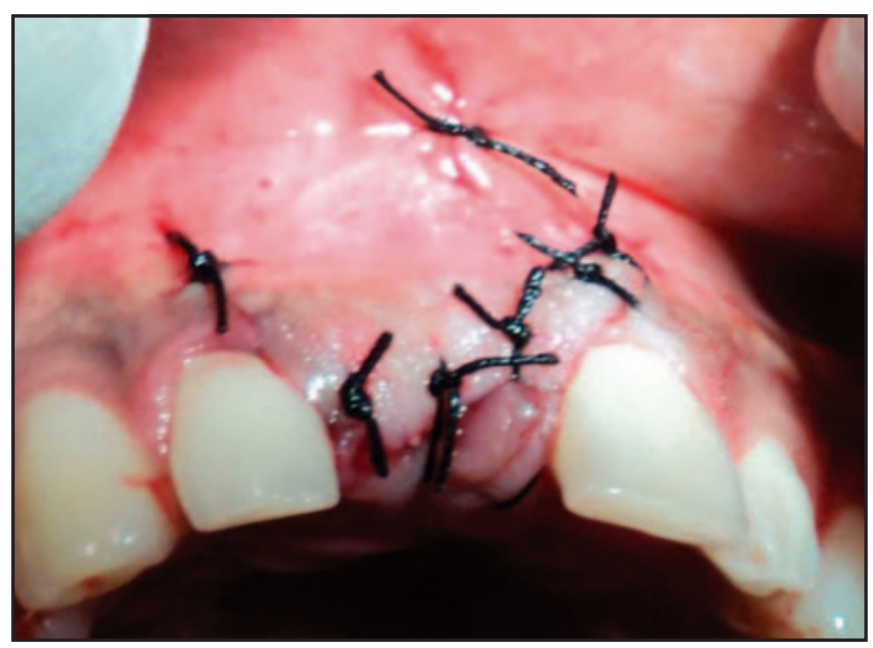

Fig. 5. Se visualiza la reposición del colgajo y cierre primario de la zona con seda 3-0.

ción; así mismo, se realizó control radiográfico de OD 11.

El análisis histopatológico del tumor odontogénico refirió una masa compuesta de matriz de esmalte, dentina, cemento y tejido conectivo, con predominio de tejido dentinal y con tejido epitelial desorganizado; hallazgos que confirmaron el diagnostico de odontoma compuesto. Tres meses posteriores a la enucleación del odontoma y colocación del injerto aloplástico, el paciente no presentó sintomatología ni complicaciones. El espacio edéntulo resultante se restauró con una prótesis fija tipo Maryland ante la imposibilidad económica por parte del paciente para colocarse un implante dental (Figura 6).

\section{DISCUSIÓN}

Se presentó un odontoma compuesto en zona anterior del maxilar superior, asintomático, provocando una ligera expansión de la cresta ósea con persistencia del órgano dental temporal, coincidiendo estos hallazgos con los descritos por Vlcek D y cols. (7), quienes confirmaron además, que las lesiones en general son hamartomas (malformación del tejido local y sin posibilidades de crecimiento autónomo) y no son neoplásicos, y que el tipo compuesto está formado por un número variable de estructuras parecidas a dientes y la histología muestra tejidos dentales en un patrón ordenado, factor que los diferencia del tipo

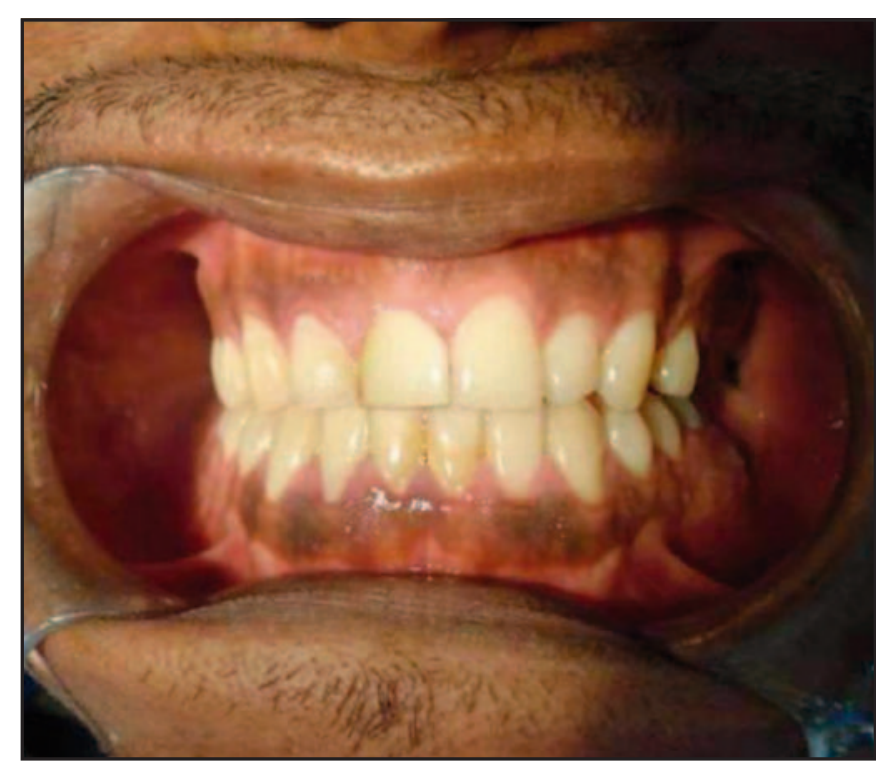

Fig. 6. Control postoperatorio a los 90 días de la intervención quirúrgica y restauración protésica definitiva.

complejo. Por lo general se diagnostica durante exámenes radiográficos de rutina o debido a la erupción tardía de dientes permanentes por la persistencia de los dientes deciduos; como se presentó en éste caso clínico, también, la mayoría de los odontomas se asocian a alteraciones patológicas en los dientes vecinos como: desvitalización, aplasia, malformación, reabsorción e impactación $(2,8)$. Los odontomas deben ser removidos quirúrgicamente, seguidos del estudio histológico que proporciona el diagnóstico de certeza. Es importante su exéresis con el fin de favorecer la erupción de los dientes permanentes, más aún, prevenir la formación de quistes y posible conversión en odontoameloblastoma, fibroma ameloblástico, fibroodontoma ameloblástico $(2,9)$.

El relleno de los defectos óseos residuales creados por la enucleación de tumores odontogénicos o quistes, es una cuestión que hoy en día no es frecuentemente valorada para su adecuado tratamiento. Sin embargo, para tratar dichos defectos y cicatrización de heridas, se ha recurrido a diversos materiales de sustitución ósea, en donde se citan los injertos aloplásticos. Estudios previos $(5,10,11)$ han recurrido a la hidroxiapatita no reabsorbible con el fin de eliminar el espacio muerto limitando dicho defecto óseo, evitar el crecimiento invertido de la mucosa y crear un plano firme al diente retenido hasta su posición 
en el arco dentario. La hidroxiapatita es un material sintético, de uso más frecuente debido a su composición química, similar a la del hueso humano, su microestructura puede ser controlada para promover la formación de poros que permitan la migración de los vasos sanguíneos y los tejidos óseos en el material (11), por lo que se usa para contorneo del hueso, aumentar la altura de la cresta alveolar, corrección de destrucciones óseas, dar retención, soporte y estabilidad a las prótesis totales; la reabsorbible forma una matriz que provoca el depósito del hueso alveolar y la no reabsorbible al ser osteoconductiva, provoca una fibrosis que sostiene el material al hueso y tejidos circundantes (12).

En el caso clínico anteriormente descrito, se empleó hidroxiapatita no reabsorbible en forma de gránulos porosos con óptimos resultados; hallazgos compatibles con Shankar R y cols., (13) quienes evaluaron la formación de hueso nuevo, eficacia y potencial regenerativo del injerto de hidroxiapatita porosa en defectos óseos, sus resultados indicaron que dicho material de sustitución ósea es biocompatible y no alergénico. Guda T y cols. (11) combinaron este mismo injerto con membrana de colágeno permeable en la regeneración de grandes defectos óseos, su uso proporcionó beneficios para la regeneración de tejido en términos de integración interfacial temprana. Finalmente, el uso de este material es ventajoso sobre otros injertos óseos debido a la simplicidad de aplicación, la eficacia de coste y fácil disponibilidad, además de la resorción completa y la formación de nuevo hueso que se evidenció en el presente caso clínico.

En conclusión, un diagnóstico adecuado y precoz ante este tipo de tumores odontogénicos, a través de la exploración clínica, radiográfica y la confirmación histopatológica, permite la resolución eficaz del tumor mediante su enucleación. Así mismo, los resultados del tratamiento quirúrgico del anterior caso indican que la respuesta clínica y radiográfica cuando se utilizó hidroxiapatita no reportó complicación adversa alguna, existiendo una excelente respuesta de curación quirúrgica. Por tanto, puede ser utilizado con éxito como complemento en la gestión de defectos óseos residuales a la enucleación de un odontoma compuesto maxilar, siendo beneficioso para el paciente.

\section{BIBLIOGRAFÍA}

1. Campos EDSTR. Odontoma complejo extenso asociado a tercer molar retenido en base de mandíbula: Relato de Caso Clínico. Acta Odontol. Venez 2011;49:1-9.

2. Yadav M, Godge P, Meghana SM, Kulkarni SR. Compound odontoma. Contemp Clin Dent 2012; 3:S13-5.

3. Ruiz RF, Sánchez ES, Vico RMY, Lagares DT, Pérez JLG. Odontoma compuesto asociado a canino permanente inferior incluido. Gaceta dental: Industria y profesiones 2013:120-27.

4. Treviño AG, Puerta PL, Ramírez HM. Odontoma compuesto: Diagnóstico radiológico y tratamiento quirúrgico de un caso. Revista ADM. 2012;69: 139-41.

5. Quintana Díaz JC. Utilización de la hidroxiapatita en cirugía maxilofacial: Actualización bibliográfica. Rev Cubana Estomatol 1998;35:16-20.

6. Tortolini P, Rubio S. Diferentes alternativas de rellenos óseos. Av Periodon Implantol 2012;24: 133-8.

7. Vlcek D, Reichart PA, Bosshardt DD, Sleiter R, Bornstein MM. [Prevention of the eruption of an upper later incisor by a compound odontoma. Case report]. Schweiz Monatsschr Zahnmed 2012; 122:1147-60.

8. Conti G, Franchi L, Camporesi M, Defraia E. Treatment protocol for the impaction of deciduous maxillary anterior teeth due to compound odontoma. Eur J Paediatr Dent 2012;13: 337-41.

9. Sreedharan S, Krishnan IS. Compound odontoma associated with impacted maxillary incisors. J Indian Soc Pedod Prev Dent 2012;30:275-8.

10. Quintana Díaz JC, Castillo Coto A, Fernández Fregio MJ. Odontoma compuesto como causa de retención dentaria: Presentación de un caso. Rev Cubana Estomatol. [Edición electrónica]. 2006 [citado 29 abril 2013]; 43: [aprox 1 pág.]. 
Disponible en: http://bvs.sld.cu/revistas/est/ vol43_2_06/est11206.htm

11. Guda T, Walker JA, Singleton BM, Hernandez JW, Son JS, Kim SG, et al. Guided bone regeneration in long-bone defects with a structural hydroxyapatite graft and collagen membrane. Tissue Eng Part A. En prensa 2012.

12. Huete Vásquez R. Manejo del alveolo en el sector anterior mediante un injerto de hidroxiapatita no reabsorbible. Revista Científica Odontológica 2010.

13. Huete Vásquez R. Manejo del alveolo en el sector anterior mediante un injerto de hidroxiapatita no reabsorbible. Rev Cien Odontol. [edición electrónica]. 2010 [citado 29 abril 2013]; 4: [aprox 1 pág.]. Disponible en: http://www.colegiodentistas. org/revista/index.php/revistaodontologica/article/ view/73/148.

14. Shankar R, Singh D, Shaikh S, Singh G, Yadav A, Jain $R$. Bone regeneration in osseous defects using hydroxyapatite graft and the extent of ossification in osseous defects treated without grafts: a comparative evaluation. J Maxillofac Oral Surg 2011;10:123-6.

\section{CORRESPONDENCIA}

Antonio Díaz Caballero

Facultad de Odontología. Universidad de Cartagena Campus de la Salud Zaragocilla

Cartagena. Bolívar. Colombia

Correo electrónico: adiazc1@unicartagena.edu.co 